\title{
A tradução para o português dos socioletos literários da trilogia Fundação, de Isaac Asimov
}

\author{
Nilfan Fernandes da Silva Júnior* \\ Daniel Padilha Pacheco da Costa ${ }^{\star *}$
}

\begin{abstract}
Resumo
Dentre todos os temas estudados nas obras de ficção científica em geral, um dos mais negligenciados pela crítica literária parece ter sido a tradução das variedades sociolinguísticas, que constituem importantes elementos na composição da verossimilhança interna de seus universos fictícios. Como afirmado pela pesquisadora canadense Lane-Mercier (1997), os chamados "socioletos literários" podem manifestar diversos atributos de um personagem, seus valores e atitudes como: educação, origem, classe, etnia, gênero, poder, cultura, instituição, valores sociais e atitudes. O foco principal deste artigo reside em algumas das variedades sociolinguísticas utilizadas na trilogia da Fundação (Fundação, Fundação e Império e Segunda Fundação), de Isaac Asimov - um clássico da ficção científica futurística. A fim de compor personagens e civilizações mais verossímeis, Asimov fez uso literário de diferentes variedades sociolinguísticas, segundo a noção de socioleto literário. Dentre dos socioletos literários mais notáveis, foram analisados o tecnoleto religioso dos sacerdotes e o dialeto rural do personagem Narovi. Nossa análise se debruçou sobre a mais recente tradução para o português da trilogia Fundação (2009 - Aleph), realizada por Fábio Fernandes e Marcelo Barbão.
\end{abstract}

Palavras-chave: Fundação. Isaac Asimov. Ficção científica. Tradução. Socioletos literários.

\footnotetext{
* Mestre em Estudos Literários pela UFU-PPLET (UFU). Graduado em Licenciatura Português-Inglês pela Universidade Federal do Triângulo Mineiro (UFTM) e Tradução pela Universidade Federal de Uberlândia (UFU).

* Professor do Programa de Pós-Graduação em Estudos Literários e do Curso de Graduação em Tradução do Instituto de Letras e Linguística da Universidade Federal de Uberlândia (UFU). Pesquisador convidado e pós-doutor durante o ano de 2020-2021 pelo Departamento de Linguística e Tradução da Universidade de Montreal (Quebec, Canadá). Doutor pelo Departamento de Letras Modernas da Universidade de São Paulo (Programa de Estudos Linguísticos, Literários e Tradutológicos em Francês), com estágio doutoral durante o ano de 2011-2012 na Universidade Paris-Sorbonne (Paris IV). Pesquisador em Literatura Comparada e Tradução. E tradutor do inglês e do francês.
}

Cadernos CESPUC de Pesquisa. Série Ensaios. n.38, 10 Sem./2021, p. 81-100. e-ISSN: 2358-3231 (OJS). Recebido em: 01/07/2021. Aceito em: 27/08/2021. 


\title{
The Translation to Portuguese of The Literary Sociolects in Foundation Trilogy, by Isaac Asimov
}

\author{
Nilfan Fernandes da Silva Júnior \\ Daniel Padilha Pacheco da Costa
}

\begin{abstract}
Among all the themes studied in Science Fiction works in general, the translation of linguistic varieties is one of the less regarded by literary criticism. These varieties constitute an important element in the composition of the internal verisimilitude in these fictional universes. The so-called "literary sociolects" can express many attributes of a character, such as: education, origin, class, ethnicity, gender, power, culture, institution, social values and attitudes. This paper mainly focuses on the linguistic varieties of Isaac Asimov's Foundation trilogy (Foundation, Foundation and Empire, and Second Empire). In order to create more realistic characters and civilizations, Asimov used different literary and linguistic varieties, according to the notion of literary sociolect, which was defined by the Canadian scholar Lane-Mercier. Among the most remarkable literary sociolects, we analyzed the religious technolects used by priests and the rural dialect of the character Narovi. The research corpus is based on the latest translation into Portuguese of the Foundation trilogy (2009 - Aleph) by Fábio Fernandes and Marcelo Barbão.
\end{abstract}

Keywords: Foundation. Isaac Asimov. Science fiction. Translation. Literary sociolects. 


\section{Introdução}

A bibliografia na área dos estudos das variedades sociolinguísticas nos gêneros literários ainda não é muito extensa, e só recentemente vem ganhando espaço nos estudos acadêmicos. O mesmo pode ser dito de Isaac Asimov e de sua grande obra mais conhecida, a trilogia Foundation ${ }^{1}$ (1951-1952). A maioria das pesquisas existentes enfatiza a relação do homem com a máquina e as diversas inteligências artificiais que ele criou, especialmente em seus contos sobre robôs, ou é voltada para a relação entre história e ficção científica de maneira abrangente. No entanto, pouca atenção se deu ao fato de que, para compor o seu vasto universo fictício, interessado não apenas pelos dispositivos tecnológicos, mas também pelas transformações sociais sofridas em um futuro imaginário distópico de um "romance sociofuturista", ${ }^{2}$ o autor explorou sistematicamente, como recurso narrativo, as variedades sociolinguísticas, com o intuito de conferir verossimilhança a seus personagens e produzir diversos efeitos estéticos.

As variedades sociolinguísticas empregadas na trilogia Fundação, de Isaac Asimov, manifestam diversos atributos, como o caráter/ personalidade de cada personagem ou civilização - arrogância, astúcia, inteligência, simplicidade -, condições do mundo real - classe, etnia, gênero, poder, cultura, instituição - ou, ainda, valores e atitudes condescendência, distância, respeito, solidariedade e subversão. As variedades sociolinguísticas permitem caracterizar os personagens, vinculando seus falares a determinadas comunidades linguísticas. Os efeitos produzidos por essas variedades não se limitam à verossimilhança, mas também incluem a comicidade e o exotismo, por exemplo. Muitos personagens apresentam jargões próprios ligados a identidades culturais específicas, como a política, a tecnologia e o militarismo.

\footnotetext{
1 A trilogia é composta pelos livros Foundation (Fundação), Foundation and Empire (Fundação e Império) e Second Foundation (Segunda Fundação), originalmente publicada nos anos 1940 na revista pulp fiction, Astounding Science Fiction, e posteriormente em formato de livros pela Gnome Press durante os anos 1950. Nessa pesquisa, o texto em inglês foi retirado das edições paperback da Bantam Book.

2 A trilogia Fundação, um clássico da Era de Ouro da ficção científica, foi aclamada pela crítica, recebeu uma legião de fãs e pode ser considerada um cânone do subgênero ficção científica social. Firmemente apoiado em conceitos políticos, ideológicos, históricos e culturais, Asimov se espelhou na própria sociedade americana pós-Segunda Guerra Mundial. A Fundação começa com a iminente queda do Império Galáctico e a luta de um grande cientista que desafiou o status quo para tentar salvar a civilização, criando uma Fundação nos confins da galáxia com o intuito de compilar todo o conhecimento humano. A história se desenrola no decorrer de centenas de anos, entremeada de conflitos políticos, guerras, reviravoltas sociais e diversos heróis que mudam a cada capítulo, porém sem nunca abandonar todo o cavalheirismo típico das histórias pulp fiction e da Era de Ouro.
}

A tradução para o português dos socioletos literários da trilogia Fundação, de Isaac Asimov 
Neste artigo, pretende-se propor uma análise da tradução para o português das variedades sociolinguísticas que, presentes na trilogia Fundação, de Isaac Asimov, permitem caracterizar seus personagens cultural e socialmente, identificando-os a estratos sociais, a profissões e, até mesmo, a civilizações. Apesar de existirem outras duas traduções no mercado - uma tradução portuguesa da editora Ulisseia (1962) e outra tradução brasileira da extinta editora Hemus (1982) -, optou-se por trabalhar com a tradução realizada por Fábio Fernandes (Fundação, vol. 1, e Fundação e Império, vol. 2) e Marcelo Barbão (Segunda Fundação, vol. 3), publicada em 2009, pela Editora Aleph, já que essa tradução não apenas é a mais recente, mas também, pelo seu esmero, a tradução de referência no Brasil.

\section{As variantes sociolinguísticas}

Diferentes pesquisadores definem o conceito de dialeto como uma variedade linguística regional ou geográfica que, geralmente, é associada a um sotaque específico (cf. CARVALHO, 2006). Conforme Richards e Platt (PLATT; RICHARDS, 1993, p. 107, tradução nossa), o dialeto se refere a:

[...] uma variedade de uma língua, falada em uma parte de um país (dialeto regional), ou por pessoas pertencentes a uma classe social específica (dialeto social ou SOCIOLETO), que difere em algumas palavras, gramática e/ou pronúncia de outras formas da mesma língua.

Um dialeto é frequentemente associado a um SOTAQUE em particular. Algumas vezes um dialeto ganha status e se torna a VARIEDADE PADRÃO de um país. ${ }^{3}$

A partir disso, é possível traçar um paralelo entre "língua" e "dialeto". Língua é aquela variedade ou dialeto-padrão difundido por todo um país e compartilhado em comum entre seus habitantes que, tendo adquirido o status de "norma culta" ou "língua padrão", possui gramática e escrita bem estabelecidas, gozando de certo privilégio político-histórico-social. O

\footnotetext{
3 Original em inglês: "A variety of a language, spoken in one part of a country (regional dialect), or by people belonging to a particular social class (social dialect or SOCIOLECT), which is different in some words, grammar, and/or pronunciation from other forms of the same language. A dialect is often associated with a particular ACCENT. Sometimes a dialect gains status and becomes the STANDARD VARIETY of a country".
} 
dialeto, por sua vez, é uma "subdivisão" da língua dita padrão, limita-se a uma área geográfica específica, dispõe de diversos graus de inteligibilidade e distancia-se da gramática tradicional pelas suas variações de léxico, sintaxe, pronúncia e ortografia.

Assim como o dialeto, o socioleto também representa uma variedade linguística. Uma definição do conceito de socioleto pode ser encontrada em Lane-Mercier e Chapdelaine (1994, p. 07, tradução nossa):

De criação relativamente recente, o termo socioleto designa na sociolinguística toda linguagem particular de um (sub)grupo social determinado. Distinguindose simultaneamente dos conceitos de dialeto, que se baseia em critérios mais especificamente geográficos, de idioleto, que significa uma maneira idiossincrática, individual de falar, e de tecnoleto, que remete aos diversos campos do discurso de um estado de sociedade, os socioletos podem ser definidos a partir de critérios propriamente sociais, culturais, econômicos e institucionais.

O dialeto estaria associado a uma forma mais geral de falar ou a uma região geográfica (como é o caso do dialeto inglês de Yorkshire ou do falar nordestino brasileiro), enquanto as outras variedades linguísticas, como o socioleto, o idioleto e o tecnoleto, equivalem a falares grupais ou individuais. Dessas três variedades sociolinguísticas, o socioleto seria o mais geral, pois designa um falar de grupos específicos definido por critérios sociais, culturais, econômicos e institucionais. Devido aos amplos critérios adotados, muitos podem ser os socioletos: o falar de uma classe social (que ocupa uma determinada posição na hierarquia de uma sociedade), de uma etnia (como o dos escravos americanos, que daria origem ao Black English Vernacular), de uma determinada geração (a diferença entre o falar dos jovens e o dos mais velhos) e, até mesmo, de uma determinada região (donde a intersecção dialeto-socioleto).

Os tecnoletos, por sua vez, remetem a alguma profissão ou ramo do conhecimento, como a arte, a ciência ou os esportes. Na língua corrente, os tecnoletos são designados pelo termo "jargão" . Esse sentido do termo “jargão”, já podia ser encontrado na acepção de jargon em francês médio, como afirma Costa (2018, p. 52): "O primeiro registro de um socioleto utilizado por criminosos na França [...] [era] falado em meados do século 4 Conforme o Dicionário Houaiss da Língua Portuguesa, a palavra "jargão" designa: "Código linguístico próprio de um grupo sociocultural ou profissional com vocabulário especial, difícil de compreender ou incompreensível para os não iniciados” (HOUAISS; VILLAR, 2009, p. 1127).

A tradução para o português dos socioletos literários da trilogia Fundação, de Isaac Asimov 
XV pela quadrilha dos Coquillards". O jargon, ou o argot, como veio a ser chamado mais tarde, passou a definir principalmente o falar dos grupos sociais urbanos de classes perigosas ou marginalizadas (COSTA, 2018). Nas obras literárias, ele desempenha, entre outras funções, a de "[vincular] o enunciador a um grupo social falante de uma variedade linguística" (COSTA, 2018, p. 54).

Simultaneamente, chama-se de tecnoleto às diferentes variedades sociolinguísticas pertencentes a um ramo do conhecimento ou um campo discursivo (cf. LANE-MERCIER; CHAPDELAINE, 1994). Como será visto, os tecnoletos são bastante empregados em Fundação para caracterizar o linguajar dos sacerdotes (com seu vocabulário e construções frasais próprias). Por último, há o idioleto, que, de todos, é o menos estudado e referenciado nos estudos linguísticos e literários. Ele se refere à maneira específica de falar de um indivíduo, com todas as suas idiossincrasias, peculiaridades e vocabulários, tendo em vista os diferentes contextos comunicativos, destinatários e finalidades discursivas.

\section{A criação de socioletos literários}

As variedades sociolinguísticas são comumente transpostas para as obras literárias para produzir diferentes efeitos estéticos e ideológicos. O dialeto literário seria uma tentativa feita por autores de retratar na escrita a fala de dialetos reais, com o intuito de caracterizar personagens e produzir determinados efeitos estético-estilísticos (cf. CARVALHO, 2017). Sumner Ives assim define o conceito de dialeto literário:

Um dialeto literário é a tentativa por parte de um autor de representar na linguagem escrita uma fala que é restrita regionalmente, socialmente ou ambos. Sua representação pode consistir apenas no uso de uma alteração ocasional na ortografia, como FATHUH no lugar de father, ou o uso de uma palavra como servigrous; ou o autor pode tentar conseguir uma precisão científica representando todas as peculiaridades gramaticais, lexicais e fonéticas que observou. (IVES, 1950, p. 137).

Na literatura, a representação de um dialeto ou de qualquer outro tipo de variedade sociolinguística ou fala/escrita não padrão precisa tomar 
como ponto de comparação a própria variedade adotada pelo escritor que, elevada à norma padrão, é considerada o "grau zero" da língua. A manifestação de tal fala "desviante" ou não padrão, geralmente, evidenciase na forma de uma ortografia não padrão, deliberadamente alterada com o intuito de demonstrar aos leitores que aquela é a fala de um personagem que não está inserido no contexto da norma padrão, dito mais educado ou culto.

O socioleto literário presente no texto escrito é, assim, contrastado com a norma culta ou padrão da língua, segundo um sistema valorativo. De acordo com Barthes (2012), um dos principais campos de exploração dos socioletos na literatura se deu com os romances realistas do século XIX, preocupados com a expressão heterodiscursiva de linguagens e linguajares coletivos. Em sua grande maioria, eles foram retratados, naquela época, de maneira pitoresca e paródica. Uma importante definição de socioleto literário foi oferecida por Lane-Mercier (1997) nos seguintes termos:

O conceito de socioleto literário é interpretado aqui como a representação textual de procedimentos discursivos "não padronizados" que manifestam tanto as forças socioculturais que moldaram a competência linguística do falante, quanto os vários grupos socioculturais aos quais o falante pertence ou pertenceu. Via de regra, essas representações não padrão, aparecem no discurso direto de uma ou várias personagens, cujas configurações fonéticas, sintáticas, lexicais e/ou semânticas são assim desencadeadas, geralmente (mas, certamente, nem sempre) comparada a uma maneira negativa ou derrogatória, de uma fala socialmente "neutra", linguisticamente "correta" do narrador e, se for o caso, de outros personagens. De um modo geral, esses padrões de discursos "desviantes" são altamente estereotipados, baseados em suposições comumente compartilhadas, facilmente reconhecíveis de diferenças socioculturais e linguísticas, e mais ou menos estilizadas, contendo uma quantidade limitada de marcadores socioletais cuidadosamente selecionados e projetados para garantir que, nem a inteligibilidade nem a legibilidade dos diálogos estejam impedidas. ${ }^{5}$ (LANEMERCIER, 1997, p. 46, Tradução nossa).

\footnotetext{
5 Original em inglês: "The concept of literary sociolect is construed here as the textual representation of "non-standard" speech patterns that manifest both the socio-cultural forces which have shaped the speaker's linguistic competence and the various socio-cultural groups to which the speaker belonged or has belonged. As a rule, these non-standard patterns appear in the direct discourse of one or several characters, whose phonetic, syntactic, lexical and/or semantic configurations are thus set off, usually (but certainly not always) in a negative or derogatory mode, from the socially "neutral", linguistically "correct" discourse of the narrator and, as the case may be, of other characters. Generally speaking, these "deviant" speech patterns are both highly stereotypical, based on commonly shared, easily recognizable assumptions of socio-cultural and linguistic differences, and more or less stylized, containing a limited quantity of carefully selected sociolectal markers designed to ensure that neither the intelligibility nor the readability of the dialogues is impeded".
}

A tradução para o português dos socioletos literários da trilogia Fundação, de Isaac Asimov 
Assim definido, o conceito de socioleto literário engloba um conceito mais geral dos desvios dos padrões de fala que, correspondente aos diversos contextos e grupos socioculturais, também inclui as variações dialetais, tecnoletais ou idioletais. Tomada a definição de Lane-Mercier, num sentido amplo, o socioleto constitui um discurso não padrão que enfeixa determinados grupos e contextos socioculturais. A representação do outro nos textos literários por meio dos socioletos demonstra a heterodiscursividade constitutiva das comunidades linguísticas que, refratada pelos escritores, contestam a "suposta unidade das línguas nacionais e das ideologias dominantes” (LANE-MERCIER, 1997, p. 47, tradução nossa).

Por se tratar de usos desviantes da língua, os socioletos literários carregam valores sociais próprios das suas comunidades linguísticas de origem que, vítimas frequentes de preconceito linguístico, são refratadas em seus usos literários pelo narrador e por outros personagens. Cabe ponderar de que forma os autores representam os personagens caracterizados por esses falares: de maneira positiva? Negativa? Ou ambas? (LANE-MERCIER, 1997). A utilização de "socioletos literários" para caracterizar os falares de personagens permite, assim, definir sua dimensão estética e ideológica.

\section{A tradução de socioletos literários}

A tradução das variedades sociolinguísticas constitui um enorme desafio. Diferentes teóricos da tradução literária reconhecem que, sempre que estão diante de variedades sociolinguísticas, os tradutores esbarram em um problema de intraduzibilidade. Apesar das severas limitações impostas pelas variedades sociolinguísticas, eles recomendam aos tradutores um posicionamento ético de respeito à alteridade do texto, pois, como afirma Azevedo (2000, p. 74), "a qualidade da tradução depende de poder captar os matizes dialógicos do original, de modo a preservar, ainda que modificada, a diversidade linguística".

A fim de sair desse labirinto, estudiosos lançaram alguns fios de Ariadne que auxiliam os tradutores a desbravar esse universo de 
possibilidades. Citando Morini, Carvalho elenca quatro estratégias possíveis para a tradução de variedades sociolinguísticas:

1) traduzir o texto na norma culta da língua de chegada;

2) usar duas ou mais variantes da língua de chegada;

3) traduzir uma das variantes por uma variante não padrão da língua de chegada; e

4) a criação de uma língua-alvo sintética, composta por palavras e frases fora da norma ou ligeiramente modificadas, e por palavras e expressões regionais foneticamente adaptadas às regras da língua-alvo. (MORINI apud CARVALHO, p. 21, 2017).

Para Morini, a melhor opção seria a quarta estratégia, que é mais complexa e adaptável criativamente. A segunda e terceira estratégias seriam melhores do que a primeira, que apenas traduz para a norma culta, apesar do risco de essas traduções gerarem um distanciamento do "plano sociolinguístico" do texto original e acabarem deslocando os sentidos comportados pelo uso daquelas variedades.

Alexandra Assis Rosa (2012) descreveu da seguinte forma as principais estratégias adotadas para a tradução de variedades: 1) Normalizadora - que substitui as variedades literárias de menos prestígio do texto-fonte pela norma padrão no texto-alvo (a variedade de maior prestígio); 2) Centralizadora - as variedades estigmatizadas do textofonte são traduzidas por coloquialismos no texto-alvo, porém próximas à norma padrão; 3) Descentralizadora - quando substitui uma variedade estigmatizada da língua-fonte por outra variedade estigmatizada no textoalvo. Ainda segundo Rosa, haveria quatro categorias de traduções: 1) Omissão, 2) Adição, 3) Manutenção e 4) Mudança (quando há mudança nas variedades sociolinguísticas). Numa grande quantidade de casos, haveria "alterações e substituições de marcadores linguísticos que caracterizam variedades linguísticas” (ROSA, 2012, p. 85).

Quaisquer que sejam as estratégias adotadas pelo tradutor, elas possuem um papel decisivo para a construção da verossimilhança interna da obra, bem como para a caracterização dos personagens e para reconstrução da heterodiscursividade constitutiva do texto de partida. Como afirma Carvalho (2006, p. 28): "Identidade das personagens, o relacionamento

A tradução para o português dos socioletos literários da trilogia Fundação, 
entre elas, a situação de elocução - são esses os critérios fundamentais para embasar uma proposta de tradução de variantes dialetais". Azevedo (2000) também comenta a importância da representação dos socioletos literários e de suas traduções na construção dos personagens. Em sua análise de For Whom the Bell Tolls (1940), de Ernest Hemingway, ele depreende que "dialeto literário não é somente uma maneira alternativa de representar os mesmos conteúdos, senão que contribui poderosamente a moldar a fala dos indivíduos representados e as relações entre estes" (AZEVEDO, 2000, p. 74).

O socioleto literário, seja enquanto ato mimético de algum socioleto real ou uma criação puramente autoral para a verossimilhança interna da obra, possui poderosa carga de expressividade. Por isso, muitos estudiosos do assunto concordam com a necessidade de encontrar soluções criativas para a tradução dos socioletos literários. O apagamento ou supressão dos socioletos eliminaria a expressividade dos personagens e deformaria o texto, condenando a tradução ao etnocentrismo (BERMAN, 2007).

\section{O tecnoleto dos sacerdotes}

Os socioletos literários a serem estudados na trilogia da Fundação, de Isaac Asimov, são extraídos, em sua vasta maioria, dos discursos dos personagens, principalmente do discurso direto introduzido nos diálogos. Nos linguajares dos personagens de Fundação, são representados, ainda que implicitamente, possíveis valores e ideologias. Asimov utilizou os socioletos literários como uma grande ferramenta criativa, lúdica, estética e linguística, a fim de expor conceitos científicos, políticos e históricos que lhe eram particularmente caros. As falas de seus personagens muitas vezes revelam-se na forma de grandes alegorias das intenções sócio-políticoculturais que ele pretendia transmitir aos leitores.

$\mathrm{Na}$ trilogia da Fundação, Asimov faz uso sistemático de diversos socioletos literários, como idioletos, "dialetos visuais" (eye dialects), dialetos agrários e tecnoletos profissionais. A dubiedade idioletal do Mulo, por exemplo, evidencia o uso de um idioleto que muda ao longo do romance. Nas falas dos personagens Lord Dorwin e Homir Munn, há a exploração 
literária de dois dialetos visuais. Dentre os diferentes socioletos literários empregados por Isaac Asimov na trilogia da Fundação, destacam-se os dialetos geográficos e os tecnoletos e jargões de categorias profissionais. A título ilustrativo, foram destacados, em particular, dois socioletos, que são exemplares de cada um desses dois tipos: o dialeto regional dos fazendeiros de Rossem e o jargão religioso da classe dos sacerdotes, respectivamente. A presença de tais socioletos contribuiu para as caracterizações dos personagens - externamente, tendo em vista suas categorias sociais, e psicologicamente, observando aqueles efeitos estéticos e ideológicos produzidos pelos socioletos literários (LANE-MERCIER, 1997). As traduções para o português procuraram encontrar soluções criativas para modelar seus próprios efeitos estilísticos.

No capítulo The Merchant Princes (Os príncipes mercadores) de Foundation (cap. 4, parte V), o primeiro livro da trilogia da Fundação, pode ser encontrado um exemplo do emprego literário de um jargão religioso. Essa passagem está situada várias décadas após a morte do psico-historiador Hari Seldon, momento em que Terminus gozava não só de influência religiosa e política sob os outros planetas periféricos, mas também de influência econômica, por meio dos mestres mercadores. $\mathrm{O}$ conflito começa quando a Fundação descobre que três de suas naves com tecnologia nuclear haviam desaparecido nas proximidades da República de Korell. Nesse momento, o comerciante Hober Mallow é enviado para lá a fim de investigar o sumiço das espaçonaves e o grau de desenvolvimento tecnológico do planeta.

Chegando em Korell, Mallow e sua tripulação são envolvidos numa perigosa intriga política. O grande problema é que, em Korell, a religião é estritamente proibida e, apesar disso, um reverendo, chamado Jord Parma, aparentemente fugindo da pena de morte e de uma multidão enfurecida, consegue adentrar a espaçonave de Mallow. Ele suplica ao comandante e aos tripulantes que o deixem ficar:

The missionary's hands clasped in sudden supplication, "As you are enlightened men, save me from the heathen." The words tumbled out, "Save me from these brutes and darkened ones who raven after me and would afflict the Galactic Spirit with their crimes. I am Jord Parma, of the Anacreonian worlds. Educated 
at the Foundation; the Foundation itself, my children. I am a Priest of the Spirit educated into all the mysteries, who have come here where the inner voice called me." He was gasping. "I have suffered at the hands of the unenlightened. As you are Children of the Spirit; and in the name of that Spirit, protect me from them." (ASIMOV, 2004a, p. 222, grifo nosso)

\section{A tradução para o português por Fábio Fernandes:}

- Vós sois homens esclarecidos, salvai-me dos pagãos - as palavras começaram a sair numa torrente. - Salvai-me desses brutos e obscuros que correm em meu encalço e afligiriam o Espírito Galáctico com seus crimes. Eu sou Jord Parma, dos mundos anacreonianos. Educado na Fundação; a própria Fundação, meus filhos. Eu sou um Sacerdote do Espírito educado em todos os mistérios, que veio até aqui onde a voz interior me chamou - ele estava perdendo o fôlego. Sofri nas mãos dos ignorantes. Como vós sois Filhos do Espírito; e, em nome desse Espírito, protegei-me deles. (ASIMOV, 2009a, p. 180, grifo nosso)

Nesse excerto, foram destacadas em negrito as frases e expressões que remetem ao jargão religioso. As súplicas do reverendo foram traduzidas para o português brasileiro fazendo uso da segunda pessoa do plural, o "vós": "sois", "salvai-me", "protegei-me". No inglês, o pronome de tratamento you possui o mesmo significante tanto para a segunda pessoa do singular, quanto para a segunda pessoa do plural. Pelo contexto, o pronome you seria equivalente ao "vós" do português, já que os interlocutores do reverendo são os tripulantes da nave de Mallow. Essa escolha tradutória é compatível com o jargão da classe religiosa. Mesmo que, para nós, habitantes do século XXI, isso implique em um uso anacrônico do português, visto que praticamente nenhum brasileiro nativo utiliza a segunda pessoa do plural, o pronome "vós" contribui para produzir verossimilhança, pois, por muitos anos, essa forma de tratamento foi amplamente empregada pelos padres católicos e está contida em linguagens mais antigas e tradicionais, como na Bíblia. Isso demonstra que Jord Parma, mesmo sendo um falso reverendo, conhece bem as características linguísticas desse grupo social. Nesse caso, o conhecimento do jargão religioso não era uma característica do grupo social a que pertencia, nem uma característica pessoal do personagem, mas 
uma tentativa de emular um jargão cujo conhecimento linguístico era por ele detido.

Ao se comparar com uma fala anterior de outro sacerdote, na qual ele se refere a Your ship, pode ser destacada certa incoerência. Naquele caso, o tradutor usa um pronome possessivo da terceira pessoa do singular, "Sua [nave]", em vez da segunda pessoa do plural: "Vossa [nave]". É bem verdade que tanto a segunda pessoa do singular ("tu”), quanto a segunda pessoa do plural (vós) são hoje em dia raramente utilizados na fala do português brasileiro e são, na grande maioria das vezes, traduzidos pelos pronomes de tratamento você/vocês, que concordam com a $3^{\mathrm{a}}$ pessoa. No entanto, a manutenção dessa forma de tratamento na segunda pessoa (do singular e do plural), caída em desuso no português brasileiro, teria permitido reforçar o registro elevado de enunciação do personagem. Ao oscilar entre as formas da segunda pessoa (o "tu" e "vós") e da terceira pessoa (o "você" e "vocês"), a tradução brasileira introduziu uma marca de oralidade, que acabou se revelando contraditória com o registro elevado de enunciação do personagem.

\section{O dialeto do fazendeiro}

Em Second Foundation, o personagem Mulo, um mentálico ${ }^{6}$ que conseguiu controlar a maior parte da galáxia com mãos tirânicas, envia seus melhores soldados (o general Han Pritcher e o prodigioso militar Bail Channis) para tentar descobrir se existia mesmo uma Segunda Fundação que, pelos boatos, abrigaria uma comunidade de seres humanos como ele, com poderes mentais. Durante a jornada, Channis revela para o general que possui fortes suspeitas de que o planeta Finstrel (Tazenda, no original) seria o refúgio da comunidade de mentálicos que procuravam. O nome do planeta é um trocadilho com a expressão "Fim da Estrela” (Star's End), devido à dica dada, anos antes, por Hari Seldon. Os dois concordam em pousar num planeta vizinho, Rossem, controlado política e economicamente por Finstrel, a fim de angariar informações sobre a Segunda Fundação. Os

6 Seres humanos que possuíam o poder de ler e/ou controlar outras mentes.

A tradução para o português dos socioletos literários da trilogia Fundação, de Isaac Asimov 
rossemitas são um povo agrário, que vivia em vilas simples e possuía um peculiar dialeto rural:

He roared back through the door, which he opened a crack for the purpose: "Has the car been fed its fuel, yunker?" (ASIMOV, 2017, p. 42, grifo nosso) $[\ldots]$

"But what shall we do?" gasped the woman. "Can we offer these people hospitality? Is the dirt floor of our hovel to be theirs and the pickings of last week's hoecake?"

"Shall they then go to our neighbors?" Narovi purpled past the crimson induced by the cold and his arms in their sleek fur covering lunged out and seized the woman's brawny shoulders.

"Wife of my soul," he purred, "you will take the two chairs from our room downstairs; you will see that a fat youngling is slaughtered and roasted with tubers; you will bake a fresh hoecake. I go now to greet these men of power from outer space ... and ... and-" He paused, placed his great cap awry, and scratched hesitantly. "Yes, I shall bring my jug of brewed grain as well. Hearty drink is pleasant."

The woman's mouth had flapped idly during this speech. Nothing came out. And when that stage passed, it was only a discordant screech that issued. Narovi lifted a finger, "Old woman, what was it the village Elders said a se'nnight since? Eh? Stir your memory. The Elders went from farm to farm - themselves! Imagine the importance of it! - to ask us that should any ships from outer space land, they were to be informed immediately on the orders of the governor. (ASIMOV, 2017, p. 43-44, grifo nosso)

A tradução para o português por Marcelo Barbão foi a seguinte:

Ele gritou para trás, em direção à porta, aberta apenas com uma pequena fresta para dar passagem à voz:

- O tanque do carro está cheio, rapaz?

$[\ldots]$

- Mas o que devemos fazer? - gritou a mulher. - Podemos oferecer nossa hospitalidade a essa gente? Vamos oferecer o chão sujo de nossa casinha e os restos de comida da semana passada?

- Eles deveriam ir, então, para a casa dos nossos vizinhos? - Narovi enrubesceu 
para além da roxidão causada pela temperatura baixa enquanto seus braços, em sua cobertura lisa de peles, projetavam-se para a frente e agarravam os ombros fortes da mulher.

- Esposa de minha alma - ele ronronou -, você vai pegar as duas cadeiras de nosso quarto e trazê-las para baixo; vai pegar uma cria bem gorda e matá-la, cozinhar com tubérculos; vai preparar um pão fresco. Agora eu vou receber esses homens poderosos do espaço exterior... e... e... - ele fez uma pausa, colocou seu chapéu de lado e coçou a cabeça, hesitante. - Sim, vou trazer uma jarra de cereais fermentados. Uma bebida forte é sempre agradável.

A boca da mulher tinha se mantido aberta durante esse discurso. Nada saía. E quando a confusão acabou, ela só conseguiu emitir um gemido agudo de discordância. Narovi levantou um dedo:

- Mulher, o que foi que os Anciãos da vila disseram algumas noites atrás? Hã? Puxe pela memória. Os Anciãos foram de fazenda em fazenda (Eles próprios! Imagine a importância disso!) para nos pedir que se qualquer nave do espaço exterior pousasse, eles fossem avisados imediatamente por ordem do governador. (ASIMOV, 2009c, p. 47, grifo nosso)

Nesse trecho, é utilizado um dialeto próprio daquela região de Rossem - um "dialeto rural galáctico". Essa caracterização por "dialeto rural" se deve ao fato de ele corresponder a uma maneira mais "rústica" de falar. Ele é utilizado apenas pelos personagens do campo, não pelos grandes Anciões que administram o planeta. Esse "dialeto rural" se manifesta pelos maneirismos, expressões e palavras típicas da vida no campo, principalmente na fala do fazendeiro Narovi. Todos os presentes que ele pretende oferecer aos homens do espaço, são produtos de sua própria fazenda: a fat youngling (uma cria bem gorda), jug of brewed grain (jarra de cereais fermentados), a fresh hoecake (um pão fresco). Seu vocabulário, de certa forma, reflete a sua simplicidade por meio de palavras mais arcaicas ou específicas de determinada região.

Um hoecake é uma palavra datada para se referir a uma espécie de bolo rústico de milho, assado originalmente sobre a lâmina de uma "enxada" (hoe) e particularmente comum no Sul dos Estados Unidos, região tradicionalmente mais agrária. ${ }^{7}$ Esse prato foi simplesmente traduzido em português pelo termo genérico "pão", que não carrega as especificidades

7 Cf. Enciclopédia Britannica online. Disponível em: < https://www.britannica.com/topic/hoecake $>$

A tradução para o português dos socioletos literários da trilogia Fundação, 
culturais do texto de partida. Outro termo mais literário e datado é youngling, que se refere a um filhote de animal ou a uma criança. ${ }^{8}$ Este vocábulo foi traduzido em português por "cria”, palavra mais relacionada à criação de gado e a pessoas acostumadas ao dialeto rural. Narovi chama seu filho mais velho de yunker, uma derivação arcaica da palavra younker, para se referir a um rapaz. ${ }^{9}$ No mesmo trecho, é empregada outra palavra arcaica: se'nnight é uma antiga palavra para "semana" ${ }^{10}$ Em português, esse termo foi traduzido por "noites atrás", opção essa que apaga completamente esse sentido mais arcaizante e regional.

Além das palavras mais específicas do campo semântico rural, há outras atitudes que caracterizam o falar mais "rústico" de Narovi. Os vocativos utilizados para chamar sua esposa, como Old woman e Wife of my soul foram traduzidos para o português por "esposa de minha alma" e "mulher", respectivamente. E os seus gestos expansivos, segundo as descrições oferecidas pelo narrador em expressões como purpled, purred e seized the woman's brawny shoulders, foram traduzidos por "enrubesceu", "ronronou" e "agarravam os ombros fortes da mulher", respectivamente. Ao mesmo tempo que evitam exotizar a variedade linguística em inglês por meio de um dialeto "caipira" brasileiro, essas opções de tradução aproximam as personagens de um estereótipo do "homem do campo", conferindo-lhe um tom paródico. Apesar de ser mais regionalista e rural, seu falar não é de todo coloquial, pois, quando está numa conversa com os viajantes do espaço, ele sobe um pouco de registro e tenta mostrar cortesia e deferência.

A tradução em português não reflete esse linguajar rústico de Narovi. As palavras utilizadas nos termos acima mencionados, como "bolo de milho", "cria", "rapaz" tendem a ser mais neutras no português e poderiam ser perfeitamente enunciadas por pessoas do campo ou da cidade. $\mathrm{Na}$ tradução para o português, o caráter mais arcaizante das palavras se perde. Ao traduzir as palavras arcaizantes e os significantes específicos do fazendeiro por termos mais genéricos, segundo os padrões da língua culta, os tradutores promoveram a destruição das redes de significantes, como a chama o teórico Antoine Berman (2007).

8 Cf. Collins Dictionary online. Disponível em: <https://www.collinsdictionary.com>
9 Cf. Collins Dictionary online. Disponível em: $<$ https://www.collinsdictionary.com>
10 Cf. Collins Dictionary online. Disponível em: $<$ https://www.collinsdictionary.com> 
Ao traduzir a variedade linguística do fazendeiro Narovi e homogeneizar as suas marcas dialetais por meio do português padrão, os tradutores também promoveram o apagamento das superposições de línguas. Para Berman (2007, p. 59), isso constitui um "grave atentado à textualidade das obras em prosa", uma vez que a língua vernacular é mais corporal e icônica que a língua-padrão. A heterodiscursividade (pluralidade de línguas, falas e vozes diferentes) que caracteriza a trilogia da Fundação foi apagada e, com ela, a "[...] relação de tensão e de integração existente no original entre o vernacular e a koiné, a língua subjacente e a língua de superfície etc." (BERMAN, 2007, p. 61).

\section{Considerações finais}

$\mathrm{Na}$ trilogia da Fundação, Isaac Asimov explora literariamente diversas variedades sociolinguísticas, como dialetos (inclusive os dialetos visuais), idioletos e socioletos, que estão englobados no conceito genérico de "socioleto literário", proposto pela teórica canadense Lane-Mercier (1997). Exemplares dos socioletos literários empregados naquele romance seriam a dubiedade idioletal do Mulo, os dois dialetos visuais (eye dialects) presentes nas falas dos personagens Lord Dorwin e Homir Munn, o dialeto regional dos fazendeiros de Rossem e o jargão religioso da classe dos sacerdotes.

Todos esses socioletos literários evidenciam a heterodiscursividade constitutiva da trilogia Fundação que, caso raro entre os textos escritos no gênero da ficção científica, não deixa de testemunhar uma notável sensibilidade para a pluralidade de línguas, falas e vozes que povoam os planetas do futuro imaginado pelo escritor. No interior da acentuada heterodiscursividade disseminada pelo romance, foi selecionado, em particular, o jargão religioso da classe dos sacerdotes e o dialeto regional dos fazendeiros de Rossem.

Em sua tradução brasileira do jargão religioso dos sacerdotes, Fábio Fernandes (Fundação) conseguiu manter algumas marcas socioletais, como o emprego do "vós", por exemplo, para marcar o registro elevado de enunciação do personagem. No entanto, foram observadas algumas incoerências em sua tradução quanto ao uso dos pronomes de tratamento: 
ao oscilar entre as formas da segunda pessoa (o "tu" e "vós") e da terceira pessoa (o "você" e "vocês"), essa tradução introduziu uma marca de oralidade, que acabou se revelando contraditória com o registro elevado de enunciação do personagem.

Em sua tradução para o português do dialeto regional dos fazendeiros de Rossem, Marcelo Barbão (Segunda Fundação) evitou adotar um registro coloquial de enunciação, até porque, quando está numa conversa com os viajantes do espaço, Narovi sobe um pouco de registro e mostra domínio de registros mais elevados de enunciação. No entanto, a tradução brasileira do dialeto rural dos fazendeiros de Rossem acabou padronizando marcas distintivas desse socioleto literário, como ocorreu com os itens culturalmente marcados, além de apagar a rede de significantes presente nas palavras mais arcaicas ou específicas de determinada região, como por exemplo hoecake, traduzido pelo termo genérico "pão", em português.

Essas inconsistências no registro discursivo e na elevação do padrão da língua estão diretamente relacionados às tendências deformantes da tradução chamadas por Berman de apagamento das superposições de línguas e destruição de linguagens vernaculares. Espalhadas por diversas partes e personagens da trama, essas tendências elidiram marcas socioletais exploradas por Asimov na trilogia da Fundação, transformando a tradução brasileira em uma versão menos icônica e mais padronizada de um texto particularmente rico em refratar a heterodiscursividade da sociedade americana de meados do século XX.

\section{Referências}

ASIMOV, Isaac. Foundation. New York: Bantam Spectra, 2004a.

ASIMOV, Isaac. Foundation and Empire. New York: Bantam Spectra, 2004b.

ASIMOV, Isaac. Fundação. Tradução de Fábio Fernandes. São Paulo: Aleph, 2009a. 
ASIMOV, Isaac. Fundação e Império. Tradução de Fábio Fernandes. São Paulo: Aleph, 2009b.

ASIMOV, Isaac. Segunda Fundação. Tradução de Marcelo Barbão. São Paulo: Aleph, 2009c.

ASIMOV, Isaac. Second Foundation. New York: Del Rey, 2017.

AZEVEDO, Milton M. Monteiro Lobato e por que os sinos dobram: a tradução de um dialeto literário. Revista de Letras. Fortaleza, n. 22, p. 70 75, jan./dez. 2000.

BARTHES, Roland. O rumor da língua. São Paulo: Martins Fontes, 2012.

BERMAN, Antoine. A tradução e a letra ou o albergue do longínquo. Rio de Janeiro: 7Letras/PGET, 2007.

BRITANNICA. Disponível em: <https://www.britannica.com/topic/ hoecake>. Acesso em: 01 fev. 2021.

CARVALHO, Solange P. P. A Tradução de Variantes Dialetais: o caso Camilleri: desafios, estratégias e reflexões. Belford Roxo: Transitiva, 2017.

CARVALHO, Solange P. P. A tradução do socioleto literário: um estudo de Wuthering Heights. 2006. 218 f. Dissertação (Mestrado em Estudos Estilísticos e Literários em Inglês) - Faculdade de Filosofia, Letras e Ciências Humanas da Universidade de São Paulo, São Paulo, SP, 2006.

CHAPDELAINE, Annick; LANE-MERCIER, Gillian. Traduire les sociolectes: définitions, problématiques, enjeux. TTR, v. 07, n. 02, 1994. p. 07-10.

COLLINS DICTIONARY. Disponível em: <https://www.collinsdictionary. com>. Acesso em: 20 fev. 2021.

COSTA, Daniel Padilha Pacheco da. De Victor Hugo a Honoré de Balzac: o socioleto literário da criminalidade em tradução. Revista Brasileira de Literatura Comparada. Niterói, n. 35, p. 52-60, 2018.

HOUAISS, Antônio; VILLAR, Mauro de Salles. Dicionário Houaiss da Língua Portuguesa. $1^{\text {a }}$ ed. Rio de Janeiro: Objetiva, 2009. 1986 p.

A tradução para o português dos socioletos literários da trilogia Fundação, de Isaac Asimov 
IVES, Sumner. A Theory of Literary Dialect. Tulane Studies in English, New Orleans, v. 2, p. 137-82, 1950.

LANE-MERCIER, Gillian. Translating the Untranslatable: The Translator's Aesthetic, Ideological and Political Responsibility. Target, Amsterdam, v. 9, n. 1, p. 43-68, 1997.

MILTON, John. A tradução de romances "clássicos" do inglês para o português no Brasil. Trabalhos em Linguística Aplicada. Campinas, v. 24, Jul./Dez. 1994.

PLATT, Heidi; PLATT, John; RICHARDS, Jack. Longman Dictionary of Language Teaching \& Applied Linguistics. $2^{\text {nd }}$ ed. Harlow: Longman Group UK Limited, 1993.

ROSA, Alexandra Assis. Translating place:linguistic variation in translation. Word and text - a journal of literary studies and linguistics. Bucareste, vol. 2, Issue 2, 2012, p. 75-97. 